\title{
Validation of echocardiographic indices of right ventriclular systolic function with cardiac magnetic resonance: a comparative study
}

\author{
Suchi K Grover ${ }^{1 *}$, Darryl P Leong ${ }^{1}$, Payman Molaee², Mitra Shirazi ${ }^{2}$ Adhiraj Chakrabarty ${ }^{1}$ Amy Penhall', \\ Rebecca Perry', Majo Joseph', Joseph B Selvanayagam
}

From 2011 SCMR/Euro CMR Joint Scientific Sessions

Nice, France. 3-6 February 2011

\section{Introduction}

Right ventricular ejection fraction (RVEF) is an important predictor of outcome in heart failure patients. Although cardiac magnetic resonance (CMR) assessment of RV function is considered gold standard and echocardiographic measurement of RVEF is challenging due to its unique geometry; CMR still has limited availability in the wider community. Therefore alternative echocardiographic indices such as tricuspid annular plane systolic excursion (TAPSE), peak tricuspid annular systolic velocity (RV S') and RV fractional area change (RV FAC) have been evaluated and demonstrated prognostic value, however, comparison studies with RVEF by CMR are limited.

\section{Purpose}

Our objective was to evaluate echocardiographic indices of RV function such as TAPSE, RV S', and RV FAC and compare these with CMR assessment of RVEF and patient functional status.

\section{Methods}

We prospectively recruited 73 subjects: 56 with newly diagnosed systolic heart failure (age $55 \pm 27$ years) and 17 healthy controls (age $53 \pm 8$ years). Subjects underwent transthoracic echocardiography, CMR, both under similar loading conditions; and 6-minute walk test. Echocardiographic E and A velocities, TAPSE, RV S' and RV areas were measured in the conventional manner. Ventricular volumes were measured from cine CMR images by planimetry.

${ }^{1}$ Flinders Medical Centre, Bedford Park, Australia

Full list of author information is available at the end of the article

\section{Results}

TAPSE exhibited the strongest correlation with CMR RVEF $\left(r^{2}=0.42, p<0.001\right)$. CMR RVEF could be estimated by the equation: CMR RVEF $=(17.7 \times$ TAPSE $)+$ 17, where TAPSE is measured in centimetres. RV S' and RV FAC demonstrated only moderate correlation with CMR RVEF $\left(\mathrm{r}^{2}=0.23, \mathrm{p}<0.001\right.$ and $\mathrm{r}^{2}=0.28, \mathrm{p}=0.002$ respectively). ROC curve analysis for optimal cut-off values of RV indices in the estimation of CMR RVEF $<45 \%$ are displayed in table 1.

Left ventricular ejection fraction by CMR $\left(\mathrm{r}^{2}=0.18\right.$, $p=0.001)$, CMR RV end-diastolic volume $\left(r^{2}=0.08\right.$, $p=0.03)$, RV S' $\left(r^{2}=0.15, p=0.004\right)$ and $E^{\prime}\left(r^{2}=0.15\right.$, $\mathrm{p}=0.001$ ) were significantly associated with 6 -minute walk distance, whereas CMR RVEF, TAPSE, RV FAC, transmitral E wave velocity, E/A ratio and E/E' were not. By multiple regression analysis, left ventricular ejection fraction was the only independent predictor of 6-minute walk distance $(\mathrm{p}=0.001)$.

\section{Conclusions}

TAPSE by echocardiography most strongly correlated with RVEF by CMR; RV S' and RV FAC exhibited only moderate correlation. RV S' was the only index of RV function that was associated with functional capacity by 6-minute walk test.

Table 1 ROC curve analysis of RV indices

\begin{tabular}{lllll}
\hline Parameter & Cut-off & Sensitivity & Specificity & AUC $(\mathbf{9 5} \% \mathbf{C l})$ \\
\hline TAPSE & $<1.7 \mathrm{~cm}$ & $92 \%$ & $62 \%$ & $0.78(0.62-0.93)$ \\
RV S $^{\prime}$ & $<7.4 \mathrm{~cm} / \mathrm{s}$ & $84 \%$ & $50 \%$ & $0.77(0.65-0.88)$ \\
RV FAC & $<48 \%$ & $81 \%$ & $50 \%$ & $0.56(0.32-0.8)$ \\
\hline
\end{tabular}




\section{Author details}

${ }^{1}$ Flinders Medical Centre, Bedford Park, Australia. ${ }^{2}$ Royal Adelaide Hospital, North Terrace, Australia.

Published: 2 February 2011

doi:10.1186/1532-429X-13-S1-075

Cite this article as: Grover et al:: Validation of echocardiographic indices of right ventriclular systolic function with cardiac magnetic resonance: a comparative study. Journal of Cardiovascular Magnetic Resonance 201113 (Suppl 1):075.

Submit your next manuscript to BioMed Central and take full advantage of:

- Convenient online submission

- Thorough peer review

- No space constraints or color figure charges

- Immediate publication on acceptance

- Inclusion in PubMed, CAS, Scopus and Google Scholar

- Research which is freely available for redistribution

Submit your manuscript at www.biomedcentral.com/submit 